\title{
GAMBARAN TINGKAT RISIKO PENYAKIT KARDIOVASKULAR BERDASARKAN SKOR KARDIOVASKULAR JAKARTA
}

\author{
Ida Rosidawati ${ }^{1}$, Hana Ariyani ${ }^{2}$ \\ ${ }^{12}$ Fakultas Ilmu Kesehatan Universitas Muhammadiyah Tasikmalaya
}

Article Information

Received: Agustus 2021

Revised: November 2021

Available online : Januari 2022

Keywords

Penyakit kardiovaskular, Skor kardiovaskular

jakarta, Tingkat risiko

Correspondence

Phone: (+62)81321008796

E-mail: ida.rosidawati@umtas.ac.id

\begin{abstract}
Penyakit kardiovaskular masih menjadi masalah kesehatan global di dunia termasuk Indonesia. Hal tersebut dapat meningkatkan angka kesakitan, kecacatan dan beban sosial ekonomi. Oleh karena itu, diperlukan deteksi dini risiko penyakit kardiovaskuler menggunakan skor kardiovaskular Jakarta sehingga dapat dikaji lebih lanjut, dimonitoring dan diberikan intervensi yang tepat. Penelitian ini bertujuan untuk menggambarkan tingkat risiko penyakit kardiovaskuler berdasarkan skor kardiovaskuler Jakarta. Jenis penelitian deskriptif kuantitatif dengan sampel berjumlah 30 orang menggunakan teknik accidental sampling. Pengumpulan data menggunakan lembar observasi berdasarkan skor kardiovaskuler Jakarta kemudian di analisis secara univariat. Hasil penelitian menunjukkan tingkat risiko penyakit kardiovaskular responden berdasarkan skor kardiovaskuler jakarta antara tingkat risiko rendah (43\%) dan tinggi (40\%) berbeda tipis. Peneliti berasumsi bahwa hal tersebut dipengaruhi oleh beberapa faktor yang menjadi kriteria dalam penilaiannya, sebagaimana data yang ditemukan yakni semua responden adalah perempuan (100\%), sebagian besar rentang usia adalah diatas 60 tahun (30\%), mayoritas memiliki tekanan darah normal $(66,7 \%)$, indeks massa tubuh pada kisaran $26,00-$ 29,99 (46,7\%), tidak merokok (100\%), tidak menderita diabetes mellitus (90\%), dan melakukan aktivitas fisik sedang (46,7\%). Kesimpulan Sebagian besar responden memiliki tingkat risiko penyakit kardiovaskular yang rendah dan tinggi hampir sama, sehingga manajemen faktor risiko tetap perlu dilakukan terutama pada kelompok dengan risiko tinggi.
\end{abstract}




\section{PENDAHULUAN}

Penyakit kardiovaskular masih menjadi masalah kesehatan global di seluruh dunia termasuk Indonesia (Rilantono, 2012). Data WHO tahun 2015 dalam Yusvita dan Shinta (2018) menunjukkan bahwa 70\% kematian di dunia disebabkan oleh Penyakit Tidak Menular (39,5 juta dari 56,4 kematian). Dari seluruh kematian akibat Penyakit Tidak Menular (PTM) tersebut, $45 \%$ nya disebabkan oleh Penyakit jantung dan pembuluh darah, yaitu 17.7 juta dari 39,5 juta kematian. Menurut Kementerian Kesehatan RI (2014), jumlah penderita penyakit kardiovaskular di Indonesia meningkat secara terus menerus, hal tersebut berakibat pada peningkatan angka kesakitan, kecacatan dan beban sosial ekonomi bagi penderita, keluarga, masyarakat dan negara.

Hasil dari Riset Kesehatan Dasar (Riskesdas) 2018 prevalensi penyakit jantung koroner pada penduduk semua umur berdasarkan diagnosis dokter sebesar $1,5 \%$ sedangkan di Jawa Barat sebesar 1,6\%. Prevalensi berdasarkan jenis kelamin adalah perempuan sebesar 1,6\% dan laki-laki sebesar 1,3\% sedangkan prevalensi berdasarkan tempat tinggal adalah penduduk yang tinggal di Perkotaan sebesar 1,6\% dan di Pedesaan sebesar $1,3 \%$. Prevalensi berdasarkan tingkat pendidikan ironisnya paling banyak tamat perguruan tinggi sebesar 2,1\% sedangkan berdasarkan pekerjaan paling banyak PNS/TNI/Polri/BUMN/BUMD sebesar 2,7\%. Sample Registration System (SRS) Indonesia tahun 2014 menunjukkan PJK merupakan penyebab kematian tertinggi kedua setelah stroke, yaitu sebesar 12,9\% dari seluruh penyebab kematian tertinggi di Indonesia. Data BPJS menunjukkan adanya peningkatan biaya kesehatan untuk PJK dari tahun ke tahun. Pada tahun 2018 PJK menghabiskan dana BPJS sebesar 9,3 Triliun. Hal ini menunjukkan besarnya beban negara terhadap penanggulangan PJK, yang seharusnya dapat dikendalikan dengan mengendalikan faktor risiko.

Penyakit Jantung Koroner(PJK) adalah gangguan fungsi jantung akibat otot jantung kekurangan darah karena adanya penyempitan pembuluh darah koroner. Secara klinis, ditandai dengan nyeri dada atau rasa tidak nyaman di dada atau dada terasa tertekan berat ketika sedang mendaki/kerja berat ataupun berjalan terburu-buru pada saat berjalan di jalan datar atau berjalan jauh. Penyakit jantung koroner terdiri dari penyakit jantung koroner stabil tanpa gejala, angina pektoris stabil, dan Sindrom Koroner Akut (SKA). Penyakit jantung koroner stabil tanpa gejala biasanya diketahui dari skrining, sedan gkan angina pektoris stabil didapatkan gejala nyeri dada bila melakukan aktivitas yang melebihi aktivitas sehari-hari. Komplikasi dari penyakit jantung adalah kecacatan hingga mengakibatkan kematian sehingga diperlukan upaya pencegahan penyakit jantung (Kasron 2012; Rilantono, 2012).

Pemerintah dalam pencegahan dan pengendalian penyakit tidak menular termasuk PJK, fokus pada upaya promotif dan preventif dengan tidak meninggalkan upaya kuratif dan rehabilitatif. Diantaranya dengan Gerakan Masyarakat Hidup Sehat (GERMAS) sesuai dengan Instruksi Presiden Nomor 1 Tahun 2017, yang difokuskan pada kegiatan deteksi dini, peningkatan aktivitas fisik serta konsumsi buah dan sayur. Oleh karena itu, diperlukan deteksi dini risiko penyakit jantung dan pembuluh darah melalui deteksi faktor risiko, memperkirakan tingkat risiko sehingga dapat dikaji lebih lanjut, dimonitoring dan diberikan intervensi yang tepat. Faktor risiko PJK dibagi menjadi dua yaitu faktor yang tidak dapat dimodifikasi dan faktor yang dapat 
dimodifikasi. Faktor risiko yang dapat dimodifikasi antara lain seperti: merokok, hipertensi, hiperlipidemia, diabetes mellitus, stress, diet tinggi lemak, dan kurangnya aktivitas fisik. Faktor-faktor risiko ini masih dapat diubah, sehingga berpotensi dapat memperlambat proses aterogenik sedangkan faktor risiko yang tidak dapat dimodifikasi antara lain usia (pria $\geq 55$ tahun, perempuan $\geq 65$ tahun), jenis kelamin, suku/ras, dan riwayat penyakit keluarga. Dengan demikian dapat disimpulkan bahwa modifikasi faktor risiko terbukti mengurangi morbiditas dan mortalitas pada orang dengan diagnosis atau tidak terdiagnosis penyakit jantung dan pembuluh darah jantung (Kasron 2012; Rilantono, 2012; PERKI, 2015).

Penilaian risiko penyakit kardiovaskular menggunakan skor kardiovaskular Jakarta. Dimana penilaian penentuan skornya merupakan modifikasi dari studi Framingham berdasarkan jenis kelamin, usia, tekanan darah (kriteria JNC-6), merokok, diabetes, indeks massa tubuh (IMT) dan aktivitas fisik mingguan (Kemenkes, 2017). Hasil penelitian Saraswati dan Lina (2020) membuktikan bahwa ada hubungan jenis kelamin, umur , tekanan darah, Indeks Massa Tubuh (IMT) dan aktifitas fisik dengan risiko menderita penyakit jantung berdasarkan skor kardiovaskuler Jakarta.

Kelompok Ibu-ibu Aisyiyah merupakan salah satu kumpulan para ibu-ibu pengajian di Kota Tasikmalaya yang memiliki faktor resiko tinggi untuk mengalami penyakit kardiovaskuler dikarenakan usia paling banyak diatas 45 tahun, dimana sudah banyak yang mengalami menopause, berat badan berlebih dan aktivitas fisik yang kurang, sehingga diperlukan upaya pencegahan melalui deteksi dini. Oleh karena itu diperlukan penelitian untuk melihat gambaran tingkat risiko penyakit kardiovaskuler berdasarkan skor kardiovaskuler Jakarta pada kelompok ibu-ibu Aisyiyah di Kota Tasikmalaya.

\section{METODE}

Desain penelitian menggunakan deskriptif kuantitatif. Sampel dalam penelitian ini sebanyak 30 orang dengan menggunakan teknik accidental sampling (Notoatmodjo, 2010). Pengumpulan data menggunakan lembar observasi berdasarkan Skor Kardiovaskuler Jakarta dengan Tingkat sensitifitas $77,9 \%$ dan spesifikasi $90 \%$ dengan nilai prediksi positif adalah 92,2 dan nilai prediksi negatif adalah 72,8\%, dibandingkan dengan hasil studi flamingham (Kusmana, 2017). Penilaian risiko merupakan jumlah dari faktor-faktor yang termasuk dalam skor kardiovaskular Jakarta, yaitu risiko rendah : (skor $\leq 1$ ), risiko sedang (skor 2-4), risiko tinggi (skor $\geq 5$ ). Analisa data yang dilakukan adalah analisa univariat, proporsi digunakan untuk melihat persebaran berdasarkan jenis kelamin, usia, tekanan darah, indeks massa tubuh, riwayat merokok, diabetes, aktivitas fisik.

\section{HASIL}

Karakteristik responden dilihat dari jenis kelamin, umur, tekanan darah, indeks massa tubuh, perilaku merokok, diabetes mellitus, dan aktivitas fisik. Umumnya semua responden adalah perempuan (100\%), sebagian besar rentang usia umum adalah diatas 60 tahun (30\%), mayoritas memiliki tekanan darah normal $(66,7 \%)$, massa tubuh indeks pada kisaran 26,00-29,99 (46,7\%), tidak merokok (100\%), tidak menderita diabetes mellitus (90\%), dan melakukan aktivitas fisik sedang $(46,7 \%)$. Lebih detail di tabel 1 
Sedangkan tingkat Risiko penyakit antara tingkat risiko rendah dan tinggi kardiovaskular responden berdasarkan skor berbeda tipis yaitu sebesar $43 \%$ untuk risiko kardiovaskuler jakarta menemukan bahwa rendah dan $40 \%$ untuk risiko tinggi (tabel 2 ).

Table 1. Karakteristik Responden

\begin{tabular}{|c|c|c|c|}
\hline \multicolumn{2}{|l|}{ Karaktersitik Responden } & \multirow{2}{*}{$\begin{array}{l}f \\
30\end{array}$} & \multirow{2}{*}{$\begin{array}{l}\% \\
100\end{array}$} \\
\hline Jenis Kelamin & Perempuan & & \\
\hline & Laki-laki & 0 & 0 \\
\hline \multirow{7}{*}{ Umur } & $25-34$ Tahun & 3 & 10 \\
\hline & $35-39$ Tahun & 0 & 0 \\
\hline & $40-44$ Tahun & 4 & 13 \\
\hline & $45-49$ Tahun & 2 & 7 \\
\hline & $50-54$ Tahun & 4 & 13 \\
\hline & 55 - 59 Tahun & 7 & 23 \\
\hline & $60-64$ Tahun & 10 & 34 \\
\hline \multirow[t]{5}{*}{ Tekanan Darah } & $<130 /<85 \mathrm{mmHg}$ & 20 & 67 \\
\hline & $130-139 / 85-89 \mathrm{mmHg}$ & 5 & 17 \\
\hline & $140-159$ / $90-99 \mathrm{mmHg}$ & 3 & 10 \\
\hline & $160-179 / 100-109 \mathrm{mmHg}$ & 2 & 6 \\
\hline & $>180 />110 \mathrm{mmHg}$ & 0 & 0 \\
\hline Indeks Massa Tubuh & $13,79-25,99$ & 12 & 40 \\
\hline \multirow[t]{2}{*}{ (IMT) } & $26,00-29,99$ & 14 & 47 \\
\hline & $30,00-35,58$ & 4 & 13 \\
\hline \multirow[t]{3}{*}{ Merokok } & Tidak Merokok & 30 & 100 \\
\hline & Manta Perokok & 0 & 0 \\
\hline & Perokok & 0 & 0 \\
\hline \multirow[t]{2}{*}{ Diabetes Mellitus } & Tidak & 27 & 90 \\
\hline & Ya & 3 & 10 \\
\hline \multirow[t]{4}{*}{ Aktivitas Fisik Mingguan } & Tidak Ada & 0 & 0 \\
\hline & Rendah & 10 & 33 \\
\hline & Sedang & 14 & 47 \\
\hline & Tinggi & 6 & 20 \\
\hline
\end{tabular}

Sumber : Data Primer Hasil Penelitian, 2021

Table 2. Karakteristik Responden

A. Tingkat Risiko Penyakit Kardiovaskuler Berdasarkan Skor Kardiovaskuler Jakarta

\begin{tabular}{lll}
\hline Tingkat Risiko & F & $\%$ \\
\hline Rendah & 13 & 43 \\
Sedang & 5 & 17 \\
Tinggi & 12 & 40 \\
\hline JUMLAH & 30 & 100 \\
\hline
\end{tabular}

Sumber : Data Primer Hasil Penelitian, 2021. 


\section{PEMBAHASAN}

Data Hasil penelitian menunjukkan bahwa tingkat risiko penyakit kardiovaskular responden berdasarkan skor kardiovaskuler jakarta antara tingkat risiko rendah dan tinggi berbeda tipis yaitu sebesar $43 \%$ untuk risiko rendah dan $40 \%$ untuk risiko tinggi. Peneliti berasumsi bahwa hal tersebut dipengaruhi oleh beberapa faktor yang menjadi kriteria dalam penilaiannya, sebagaimana data yang ditemukan yakni semua responden adalah perempuan (100\%), sebagian besar rentang usia adalah diatas 60 tahun (30\%), mayoritas memiliki tekanan darah normal $(66,7 \%)$, indeks massa tubuh pada kisaran 26,0029,99 (46,7\%), tidak merokok (100\%), tidak menderita diabetes mellitus (90\%), dan melakukan aktivitas fisik sedang (46,7\%).

Hal tersebut sejalan dengan teori bahwa jenis kelamin dan umur merupakan salah satu faktor risiko penyakit jantung dan pembuluh darah yang tidak dapat dimodifikasi selain ras dan riwayat penyakit dalam keluarga. Laki-laki memiliki risiko lebih tinggi dibanding perempuan hal ini senada dengan penyataan WHO (2012) yaitu risiko penyakit jantung dan pembuluh darah lebih besar pada laki-laki dari pada perempuan, namun di penelitian ini respondennya perempuan semua dengan usia sebagian besar > 60 tahun, itu berarti sudah mencapai usia menopause, dimana hormon estrogen mengalami penurunan sehingga mungkin menjadi faktor yang meningkatkan penyakit jantung pada Wanita, sejalan dengan prevalensi penyakit jantung Indonesia lebih tinggi pada perempuan sebesar 1,6\% (Riskesdas, 2018). Dan faktor resiko berdasarkan umur yaitu pada pria berumur $\geq 35$ tahun dan perempuan berumur $\geq 45$ tahun. hal ini senada dengan pernyataan dari WHO (2012) yaitu bertambahnya usia berhubungan dengan proses aterosklerosis dimana peningkatan usia meningkatkan proses aterosklerosis sehingga menimbulkan penyakit jantung dan pembuluh darah.

Tekanan darah di atas normal tergolong dalam kategori hipertensi dan perlu dijaga agar tekanan darah tetap normal. Hipertensi merupakan silent killer dan merupakan faktor utama penyakit jantung dan pembuluh darah. Tekanan darah tinggi meningkatkan risiko penyakit jantung dan pembuluh darah (Yusvita dan Shinta, 2018).

Indeks massa tubuh adalah hasil dari membagi berat badan Anda dalam kilogram dengan kuadrat tinggi badan Anda dalam meter. IMT menentukan apakah status gizi seseorang masuk dalam kategori normal, kelebihan berat badan (overweight), atau obesitas. Obesitas juga merupakan faktor risiko yang meningkatkan risiko pekerja terkena penyakit jantung dan pembuluh darah (Yusvita dan Shinta, 2018).

Merokok merupakan faktor risiko penting untuk penyakit jantung dan pembuluh darah dan dapat diperbarui atau diubah. Merokok minimal satu batang dan berhenti merokok dalam waktu satu tahun digolongkan sebagai perokok (WHO, 2012). Nikotin dalam tembakau menghasilkan katekolamin, yang menyebabkan pembuluh darah menyempit, meningkatkan detak jantung, dan meningkatkan konsumsi oksigen. Penyakit kardiovaskular merupakan penyebab kematian utama pada penderita diabetes, dengan sekitar $65 \%$ kematian penderita diabetes disebabkan oleh penyakit arteri koroner dan stroke (Bonow \& Gheorghiade, 2004; Saraswati \& Lina, 2020). Gaya hidup yang tidak sehat, seperti merokok dan gaya hidup sedentary, dapat mempercepat perkembangan aterosklerosis. Aktivitas fisik adalah gerakan tubuh yang terjadi ketika kontraksi sistem muskuloskeletal meningkatkan energi dan meningkatkan kesehatan. Ini termasuk aktivitas kerja non-harian, yaitu aktivitas fisik minimal 30 menit (olahraga ringan, 
pekerjaan rumah, naik tangga) setiap hari di kantor atau di rumah.

\section{SIMPULAN DAN SARAN}

Sebagian besar responden memiliki tingkat risiko penyakit kardiovaskular yang rendah sebanyak 13 orang (43\%), namun yang memiliki tingkat risiko tinggi juga banyak sebanyak 12 orang (40\%). Sehingga program pencegahan dan manajemen faktor risiko tetap perlu dilakukan terutama pada kelompok dengan risiko tinggi.

\section{REFERENSI}

Kasron. (2012). Kelainan dan Penyakit Jantung: Pencegahan serta Pengobatannya. Yogyakarta: Nuha Medika.

Kemenkes. (2014). Profil Kesehatan Indonesia Tahun 2014. Jakarta: Kementerian Kesehatan RI.

Kemenkes, 2017, Petunjuk Teknis Penatalaksanaan Penyakit Kardiovaskular Untuk Dokter, Kementerian Kesehatan RI Sekretariat Jenderal Pusat Kesehatan Haji Tahun 2017.

Kusmana D. (2017), Cardiac Prevention and Rehabilitation

Notoatmodjo, S., (2010). Metodologi Penelitian Kesehatan. Jakarta: Rineka Cipta.

PERKI. (2015). Pedoman Tata Laksana Pencegahan Penyakit Kardiovaskuler Pada Perempuan.

Rilantono (2012). Penyakit Kardiovaskular (PKV): 5 Rahasia, Edisi Pertama. Jakarta: Fakultas Kedokteran Universitas Indonesia.
Riskesdas. (2018). Riset Kesehatan Dasar, Badan Penelitian dan Pengembangan Kesehatan Kementerian Kesehatan RI, Jakarta.

Saraswati D \& Lina N. (2020). Faktor Risiko Penyakit Jantung Pada Masyarakat Di Pos Pembinaan Terpadu (Posbindu) Puskesmas Cibeureum. Gorontalo Journal Hearth and Science Community. Vol 4. Nomor 1.

WHO. (2012). Prevention of Cardiovascular Disease Guidelines for assessment and management of cardiovascular risk

Yusvita F \& Shinta NN. (2018). Gambaran Tingkat Risiko Penyakit Jantung Dan Pembuluh Darah Pada Pekerja Di Pt.X. Forum Ilmiah. Volume 15 Nomor 2 